Realism, reflection and responsibility: The challenge of writing effective scenarios to support the development of ethical thinking skills

Chris Ribchester *

Academic Practice Advisor

Centre for Learning and Academic Development

University of Birmingham

Contact details:

CLAD

Watson Building

University of Birmingham

Edgbaston Campus

Birmingham

B15 2TT

Tel: 01214144647

Email: c.b.ribchester@bham.ac.uk

Ruth L. Healey

Senior Lecturer

Department of Geography and International Development

University of Chester

Contact details:

Geography \& International Development

Best Building

Parkgate Road

University of Chester

Chester

CH1 4BJ

Tel: 01244513176

Email: r.healey@chester.ac.uk

* Corresponding author

Research completed at the University of Chester. 
Realism, reflection and responsibility: The challenge of writing effective scenarios to support the development of ethical thinking skills

\begin{abstract}
Universities are paying increased attention to how they might support the ethical development of their students as one of a range of graduate attributes that will enable them to negotiate increasingly complex professional, civic and personal futures. Scenario-based learning (SBL) is a longstanding strategy used in ethical teaching and this paper describes and evaluates a version of this approach as applied to a second year undergraduate tutorials module. A quantitative assessment of the development of students' ethical sensitivity over the course of two deliveries of the module shows an uneven impact but also some encouraging trends. A detailed qualitative analysis of how students responded to each scenario identifies five factors that appear to precipitate more in-depth reflection on ethical problems, and these are presented as useful points of guidance for teachers writing ethical scenarios for the first time or for those aiming to hone their existing practice. These factors include the challenge of devising circumstances which appear realistic and plausible to contemporary undergraduate students, constructing scenarios which encourage readers to reflect on and test their personal values, and portraying events which push students to intervene proactively and so taking individual responsibility for their decisions and actions.
\end{abstract}


Realism, reflection and responsibility: The challenge of writing effective scenarios to support the development of ethical thinking skills

Keywords

Ethics, scenario-based learning, tutorials, realism 


\section{Realism, reflection and responsibility: The challenge of writing effective scenarios to support the development of ethical thinking skills}

\section{Introduction}

There is a strong case for developing the capacity of all university-level students to recognise the ethical dimensions of real-world problems and to think carefully about their resolution. Ethical issues are, of course, longstanding within the content of all academic disciplines, often having their highest profile in relation to the integrity of research and the requirement to follow appropriate ethical codes and procedures (Löfström 2012; Shephard et al. 2015,). Yet the experience of the contemporary student is increasingly complex and other, non-subject specific, ethical issues have been brought into sharper focus. For example, advances in communications and database technology have raised new questions about plagiarism and freedom of information (Kayaoğlu et al. 2016; Löfström 2011; Selwyn 2008). The greater use of non-didactic forms of teaching, including increased emphasis on collaborative working, challenge students to think carefully about their personal responsibilities in the learning process (Barfield 2003; Bentley and Warwick, 2013).

However, the rationale for enhancing the ethical thinking skills of students extends beyond the increasingly permeable walls of the university. As public citizens and potential future leaders within society and the economy, equipping graduates for the ethical challenges ahead is of paramount importance. In a recent UK context, the despair expressed at the 'serious scandals that have beset our banks, political system, as well as our health and social welfare provisions' (Arthur 2014, 2) have renewed questions about the morals of those in positions of responsibility and influence, and what might be done to improve the situation (Barrow Cadbury Trust 2010; Boni and Lozano 2007).

To an extent, the HE sector appears to be acknowledging these challenges and the relatively recent discussions about the core attributes that graduates should possess often include reference to ethical, moral and social responsibility (Hill, Walkington and France 2016). At the same time, there has been growing interest in the connection between the ability to recognise and resolve ethical challenges and graduate-level employability (Barrie 2007; Robinson 2005). There is a call for enterprising, reflective, individuals with the skills and confidence to take the initiative, think critically and solve problems creatively within the fluid boundaries of the supercomplex global economy (Barnett 2000). According to the QAA the successful 'entrepreneurial mindset' includes the personal values of 'ethical, social and environmental awareness' (2012, 13). The European Commission's recently published Entrepreneurship Competence Framework lists 'ethical and sustainable thinking' (Bacigalupo et al. 2016, 11) as one of its 15 dimensions. Their definition of entrepreneurship:

applies to all spheres of life. It enables citizens to nurture their personal development, to actively contribute to social development, to enter the job market as employee or as selfemployed, and to start-up or scale-up ventures which may have a cultural, social or commercial motive. (10)

Although, by way of contrast, despite advocating the development of soft skills to meet employer needs, the recent White Paper charting out the future of UK HE (Department for Business, Innovation and Skills 2016) includes no direct reference to ethics or morals. 
This project was concerned with preparing students for the ethical challenges ahead, as a student, graduate professional and global citizen. As such the focus was not discipline-specific ethical issues, including research practice, but what might be termed 'everyday ethics'. This article provides a review of the impact of a scenario-based teaching initiative and considers the lessons that have been learnt about how to write effective ethical scenarios. It begins by providing a brief overview of existing literature about scenario-based learning (SBL) including its perceived benefits. Drawing on an existing methodology, a quantitative assessment of the impact of this initiative over a two year period is then briefly considered. This is followed by a more substantive section which uses an analysis of how students responded to different scenarios to discuss five design features which might be considered characteristic of a well-crafted scenario, i.e. one which has the potential to enhance the ethical thinking skills of students.

\section{Scenario-based learning}

Scenario-based learning (SBL) at its broadest simply refers to a teaching strategy that involves the use of scenarios to bring about desired learning outcomes (Errington 2003). Scenarios are typically presented as narratives that 'may constitute a given set of circumstances, a description of human behaviour, an outline of events, a story of human endeavour, an incident within a professional setting, or human dilemma' (Errington 2010b, 18), which the reader is required to reflect upon and devise an appropriate course of action. SBL has much in common with other teaching approaches (e.g. the use of case studies, stories, simulations) and it is clear that practitioners often use these terms inter-changeably and in different combinations. To an extent, it is possible to identify a distinction between the two most popularly used terms - scenarios and case studies (sometimes shortened to cases). Case studies tend to more detailed and lengthier than scenarios, often supplemented with additional evidence or data to scrutinise. As such case studies often outline actual events, ultimately providing the opportunity for learners to compare their decision-making with what actually happened. In contrast, scenarios tend to be presented as more open-ended, incomplete, accounts, based on fictitious or actual events, or a combination of the two (Errington 2011). Errington (2010c) distinguishes between four types of scenarios: skills-based, issues-based, speculative-based, and problem-based. The latter is closest to the approach reported in this paper, a key feature of which being the opportunity they provide to integrate theoretical understanding (in our case the different approaches to addressing ethical problems) with practical knowledge. He also notes that problem-based scenarios are good 'for engaging students in complex issues and events at a deep level over a lengthy period of time' (Errington 2010a, 56), again a characteristic of the teaching approach adopted by the authors.

The relative popularity, and perceived effectiveness, of SBL (and related approaches) is partly because it is located at the point of intersection between various high profile educational theories. For example, the connections between SBL and situated learning theory (e.g. Lave and Wenger 1991) are often cited, stressing that meaningful understanding tends to emerge when it is situated within, and can be applied to, familiar contexts. A central principle of andragogy is that 'adults learn best when the topic is relevant to them and immediately applicable' (MindTools n.d.) and multiple authors have stressed the importance of relevance as a motivator for student engagement (e.g. Ballantyne et al. 1999; Cameron 2011; Kember, Ho and Hong 2008). Scenarios can be deployed in a range of ways, but there is always a requirement to engage directly with the narratives and very commonly debate their content with others. Such active and collaborative approaches are widely 
viewed as beneficial to student learning (e.g. Cook-Sather 2010; Zepke and Leach 2010). SBL also offers the potential to deliver a penalty free, teaching environment conducive to creative, problem solving (McWilliam 2009).

SBL is reported across many disciplines, for example business (Varzaly and Baron 2009), teacher training (Sorin 2013), health education (Aitken 2010), law (Holm 2010) and engineering (Rashid and Ventura-Medina 2012). Its use as a tool to examine ethical problems is also common place with many examples shared online (e.g. Online Ethics Center for Engineering and Science 2016; The College of Optometrists 2016). Indeed Shulman (1992) notes that 'cases have been employed for thousands of years as the vehicles for enquiry and debate regarding proper ethical or moral behaviour' (7). Nickson (2010) believes that 'SBL enables students to shift from vague and general thinking [about ethics] to very concrete, real life dilemmas ... [and] ... allows students to gain a clearer insight into their own values and beliefs' (221). Well-facilitated discussions about ethical scenarios push students to display the critical thinking skills evident at the upper end of Bloom et al.'s cognitive domain (1956) and the 'organisation' and 'characterisation' of values within the affective domain (1964). It is, therefore, not surprising that the approach has been employed across a range of subjects. However, research specifically examining the impact of ethical SBL on the awareness and evaluation of ethical issues appears to be minimal, and so inevitably there also seems limited guidance available on the writing of effective ethical scenarios. Within this context, this paper provides some empirical evidence about the impact of ethical SBL, but its primary purpose is to explore the features of a welldesigned ethical scenario. The intention is to provide some practical guidance for those who want to develop this approach.

\section{The use of ethical scenarios in a tutorial context}

The initiative discussed in this paper is an addition to a long-standing second-year undergraduate tutorials module at a post-1992 UK university. Griffiths (2009) refers to the 'enormous and unique potential of the small group to promote learning' (72); in this example groups of six or seven students meeting regularly with the same tutor for the duration of the academic year. The tutorials explore different aspects of contemporary geography ${ }^{1}$, with discussions based around a questionorientated brief provided in advance, and preparation often requiring students to engage with specific readings. Each tutorial is assessed, using criteria which evaluate the level of understanding shown, oral communication and ability to interact effectively with others.

More recently a new strand of activity has been introduced to run concurrently with the tutorials structure. From the start of the module, and then roughly every two weeks subsequently, an ethical scenario is made available to the students. Each scenario requires students to make a decision on the course of action that they would follow in the fictitious circumstances described. The scenarios vary in length from 189 to 681 words, generally becoming longer and more detailed as the module progresses. Figure 1 provides a very brief summary of each scenario, which focus on 'everyday' ethical challenges which are within, or cut across, the academic, personal and professional (part-time employment) lives of students. The scenarios are chronological in that the first is set early in term one of first year moving through to the end of year two.

1 Whilst the discipline within which this initiative took place was geography, it is important to stress that the approach adopted is transferable to other teaching contexts with minimal revision, and the research findings discussed have broad applicability to scenario-based approaches across different academic subjects. 
Students are encouraged to imagine themselves into the situation outlined and then record their responses on a standard pro-forma with space to indicate their decision, the rationale for it, and how challenging they found it to arrive at a final decision. Subsequently, through the discussions in the final tutorial of the module, the students are encouraged to 'step back' from the detail of each scenario and consider how their approach to reviewing the different situations has developed over the course of module, including comparing and contrasting their approaches between scenarios.

Ultimately the purpose of the scenarios and the related tutorial discussion is fivefold: to develop the ability to recognise the ethical dimensions of a situation (ethical sensitivity); to develop the skills to think through an ethical problem (ethical decision-making); to increase awareness of common approaches ${ }^{2}$ to exploring an ethical problem; to encourage recognition of personal values; and, in the process, enhance critical thinking skills. As Hickey and Taylor (2010) note scenarios 'create a mental picture in the head of the student, a perceived reality, and students' initial, immediate reaction to a scenario reveals their values in action' (135). It is, however, stressed to the students that the purpose is not to push them to think in a particular way, arrive at a pre-defined 'correct' outcome or display particular values or character traits. In line with Clarkeburn (2002) we argue that ethics education should 'concentrate on the process of moral decision making: to support students in developing tools to recognise, analyse and solve moral problems and to create opportunities to practice these skills' (310). This would appear a plausible goal with some studies showing the positive impact of different teaching interventions on ethical decision making skills (e.g. Klugman and Stump 2006; O'Leary 2009; Ritter 2006; Self, Olivarez and Baldwin 1998).

The impact of this tutorial- and scenario-based initiative was assessed using both quantitative and qualitative data collected over a two year period with the research project being scrutinised in advance via the appropriate institutional ethical review process. In the discussion that follows, survey data which focus on how student perspectives changed over the course of both deliveries of the module are discussed firstly. Subsequently, attention turns to a detailed analysis of individual responses to each scenario.

\section{A quantitative assessment of the impact of the ethical scenarios}

Survey data was collected by drawing on a methodology developed and carefully tested by Clarkeburn et al. (2003). Their meta-ethical questionnaire (MEQ) consisted of ten bi-polar statements (Figure 2), with students responding along a five-point continuum. Each point on the scale carried a score (see example in Figure 3). The total for all ten questions was then averaged to give an overall ethical score for each student (potential range from 1 to 25). In summary, the higher the score, the more the student appears to recognise the complex, uncertain, and contingent nature of ethical decision-making, whilst showing an openness to perspectives that others offer and a willingness to take ownership of their decisions. These are perceived as desirable outcomes by the authors. All students were invited to complete the survey at the start of the module and then again after the tutorials were completed. An anonymous PIN system was used, allowing a comparison of how the

2 During an introductory teaching session, the students are introduced to five commonly-discussed approaches to exploring ethical problems and encouraged to assess their applicability when reviewing the scenarios. These are utilitarian, rights, justice, common good and virtue-based approaches (Markkula Center for Applied Ethics, 2015). 
opinions of each student changed from the beginning to end of the module. Across both years, a total of 51 students completed both the pre- and post-tutorials survey, but eight of these responses failed to meet the internal validity check incorporated into Clarkeburn et al.'s (2003) methodology. Therefore the discussion below is based on the responses from 43 students. It is recognised that this is a relatively small sample which limits the extent to which these findings can be generalised. This survey-based approach also does not attempt to disaggregate the specific impact of reading and discussing the ethical scenarios from other ongoing learning experiences both inside and outside the university. Furthermore, the use of a control group who were not participating in the tutorials module might have acted as a useful point of comparison. But nevertheless, the trends in the data collected do set an important context for the discussion of effective scenario-writing which forms the latter part of this paper.

Figure 2: Question statements

Figure 3: Example question format

The survey results show that the mean ethical score for all the students increased from 14.58 to 15.75 during the course of the module, which is statistically significant at 0.029 (Wilcoxon test). Twice as many students (28) moved to a higher ethical score between surveys compared to students whose scores moved in a downward direction (14). For one student there was no change. Male and female students showed a very similar level of increase $(+1.14$ and +1.25 respectively). Using the Mann Whitney $U$ Test, no significant difference between the male and female ethical scores was shown for the pre-tutorials survey $(0.68)$ or post-tutorials (0.94) survey. A much more detailed discussion of the quantitative data from this project is presented in Healey and Ribchester (2016).

\section{Features of a well written ethical scenario}

The brief discussion above provides an overall assessment of the effectiveness of engagement with the scenarios and suggests some development of ethical thinking skills over a relatively short period of time. This is an encouraging finding, but a key purpose of this project was also to look beyond the general trends and to try and identify scenario configurations which are likely to be most impactful on student learning. This is a challenging goal given that it is extremely unlikely that a group of students will respond to the same scenario in a uniform manner, with perspectives being shaped not only by their personal values, life experiences and critical thinking skills, but also shorter-term factors at the time they engage with the scenario, e.g. time available, mood, interest.

To explore this issue, the student written responses to each scenario were collated during the course of the module. As noted earlier, students were required to complete a standard pro-forma for each scenario by way of preparation for the tutorial discussions. Over the two years, a total of 287 proformas were collected, with at least 30 responses for most of the scenarios. Their content was then subjected to a process of careful qualitative data analysis as outlined by Cope (2010) during which the text was initially coded (descriptive codes) and then categorised (analytic codes) under three core headings for each scenario: What course of action was chosen? What was the justification for this decision? How difficult was it to reach a decision? Of particular interest were scenarios which provoked a wide variety of decisions about the 'right' course of action, more lengthy explanations to justify the decisions made, and students acknowledged were difficult to conclude on the appropriate 
course of action. The implication is that such scenarios have been able to elicit an ethical sensitivity in the students and tested their moral reasoning skills.

This data analysis approach, drawing on the principles of grounded theory (Hennink, Hutter and Bailey, 2011), provided a rich source of information revealing how students reacted to, and worked through, each scenario. However, it is important to recognise the potential limitations of the methodology. Interpreting large qualitative data sets in this way inevitably necessitates a degree of researcher subjectivity (Cousin, 2009). Although some dominant themes emerged, it is accepted that alternative interpretations might have been provided by different researchers or by tweaking the analytical approach (e.g. reviewing the scenarios in a different order). Furthermore, in creating the threefold analytical headings outlined above (decision, justification, difficulty), the analytical gaze was potentially diverted from themes that might have cut across these categories. Additionally, there is an underlying concern about the 'honesty' of the student responses, an issue that is considered further in the conclusion of this paper.

The next section considers five themes which emerged from the qualitative data analysis, presented as 'design' features which seem to characterise an effective ethical scenario.

\section{1, Realistic}

The extent to which the fictitious ethical scenarios were perceived by the students to be realistic appears to be a critical factor that affected the level of engagement with them. Realism is a topic that is frequently considered in the wider scenario-based learning and case study literature and it is therefore unsurprising that it emerges strongly here too. Deeper critical thinking about the ethics of a situation is only likely to be achieved if someone has immersed themselves within it and believes the scenario to be credible. For six of the nine scenarios a clear theme that emerged from the student responses was the extent to which their decision-making was shaped by the way that they empathised with the characters in the scenario by highlighting direct parallels with their own experiences and/or imagining themselves into their circumstances. For example, a third of the responses to scenario 2 commented on the challenges faced by students who commute to university or live at home and the implications that this can have for full participation in learning activities. Responses like this imply a degree of authenticity was achieved as students were drawn into the scenarios. We would argue that an ability to see through, and be open to, other people's perspectives and appreciate the challenges that they face is a key component of ethical thinking.

As experienced university tutors, working with students in both a teaching and pastoral context, the authors of the scenarios were in a reasonably strong position to construct narratives which appeared realistic to contemporary university students. But, as we have noted elsewhere, 'there is a danger of imposing tutor perspectives about realism and difficulty, filtered through their own values and life experiences, on to the students' (Healey and Ribchester, 2016, p.309). Errington (2011) points to the inevitable limits to the perceived realism that can be achieved by any scenario author and suggests that 'near-world' as opposed to 'real-world' is a more achievable aspiration (85). Adam (2010) notes that there 'is a dramatic quality to scenarios that have been experienced by the students or trainers in a course' (106-107) and believes that participants respond well to scenarios that are grounded in real-life experiences. However, tutors in the module did note occasional discomfort from students who were required to reflect on scenarios which apparently closely paralleled some of their own experiences. Hill et al. (2010) cautions that 'students can be quite blinkered in their attitudes to 
generic information, resisting seeing the appropriateness of a broader topic unless it has direct links to the subject of their degree' (33). To help counter this potential problem, a strategy adopted here was to ensure that there was always a link to the academic discipline within each scenario, however tenuous, and despite the largely non-subject specific ethical problems that were outlined.

\section{2, Impactful}

There is strong evidence from the student responses that deeper thinking about ethical challenges occurs when the scenarios depict a set of circumstances for which the final decision will lead to differential consequences on those within the narrative including the student themselves. Consideration of impacts is a theme in the student responses to all the scenarios. Typically, the greater the perceived impacts on themselves and others (e.g. in terms of assessment grades, livelihoods and well-being, income, social networks), the greater the level of difficulty acknowledged by the students in arriving at a final decision. The final scenario, which deliberately cut across the student academic, personal and professional 'worlds' was most commonly recognised as the hardest to resolve. The student responses, for example, emphasised the challenge of balancing the potential impacts of different decisions on their studies, future career opportunities, university reputation, farming livelihoods and the environment. That said scenario writers should be wary of devising multiple layers of problems and challenges, and consequently undermining the perceived realism of the narrative.

Across the scenarios, a minority of students consistently made a decision based on the course of action that benefitted themselves the most, largely irrespective of the consequences for others. But one of the most striking themes in the student responses was the search for compromise solutions which might plausibly benefit all stakeholders or at least minimise or spread out the potential negative consequences. Frequently students showed significant imagination and creativity in devising strategies as they carefully evaluated the consequences of their decisions. Even in the seemingly more straightforward scenarios with apparently limited options for action, it is interesting to see the diversity of tactics employed. For example, in scenario 1, although the great majority of students decided to give their new friend access to their personal notes from teaching sessions, this manifested in a range of ways, including lending them for a defined time period, providing copies, peer-to-peer discussions, and the piecemeal sharing of notes as a 'test' to see if they would be returned.

Some students recognised the search for a balanced solution as an overt adoption of a utilitarian strategy towards ethical problems. Whilst this shows an encouraging level of self-awareness, it is also clear that a strong theme underpinning the search for compromise was a concern to avoid conflict and confrontation with others in academic, professional and personal settings (evident in four of the nine scenarios). Furthermore, different courses of actions were frequently assessed against the extent to which friendships would be undermined or even the potential to generate new friendships (six scenarios). This is a good example of how engagement with a fictitious set of circumstances can bring to light real-world concerns in the daily life of students. In this case, the significance of friendship networks and supportive social relations are highlighted, which are widely recognised to be important factors affecting the persistence, retention and resilience of university students (Thomas 2012; Wilcox, Winn and Fyvie-Gauld 2005). The relative difficulty reported by students when the scenario decision-making had potential implications for their own or other's assessment 
grades (e.g. scenarios 2 and 3) is another good example of this, highlighting the centrality of assessment, and especially marks, to the contemporary student experience (Race 2014; Sambell 2016).

\section{3, Encourages reflection on personal values}

A key motivation for this initiative about ethical thinking was to enhance students' awareness of their personal values, how these might vary from others, and what implications this might have. Therefore, it is important that a well-constructed scenario provides the opportunity for students to reflect on circumstances which allows them to draw out and test their values, and consider whether they are as virtuous as they might believe or would like themselves to be. As probably the most straightforward example of this, a number of the scenarios offered circumstances which allowed for positive outcomes for the majority of stakeholders as a consequence of choosing, often covertly, a dishonest course of action, e.g. lying to friends. For example, scenario 4 explored these possibilities by providing students the opportunity to falsify primary data in a fieldwork context, a decision which just over half the students opted for. At face value this might seem a troubling outcome but this option was often carefully justified with reference to the wider benefit to the student group as a whole and the personal 'learning from mistakes' that would occur.

Analysis across the scenarios allows for an assessment of the extent to which students adopted a deontological, principle-based, approach to resolving ethical problems as opposed to a more consequentialist strategy based on an assessment of impacts of different possible decisions (Taylor 2015). As might be expected, the balance did vary between scenarios with evidence of the most principled stances being taken in relation to different forms of cheating in an assessment context (e.g. scenario 5) and about honesty over money (scenario 7b), when there was a stronger concern to do 'the right thing'. However, overall, a consequentialist approach weighing up the relative short and, sometimes, longer term impacts of different decisions tended to dominate.

\section{4, Space for interpretation}

A major lesson about ethical scenario-writing that has been learnt from this project is how frequently reflection and discussion emerges from the details absent from a scenario rather than from what is included. Perhaps a little counterintuitively, it seems that a comprehensive scenario which, for example, sets a wide-ranging context, describes the motivations of all the characters in the narrative and provides full explanations for people's action typically promotes less discussion than one which allows these to be speculated upon. Occasionally the student responses reveal some frustration and disengagement because some, what might be considered, key facts are missing. But for the most part it appears that the absence of information acted as a 'springboard' for discussions, as different student assumptions and decisions about missing information were revealed. This openness also gives tutors the opportunity to change the parameters of events and characters within a scenario to test the malleability of student decision making and the limits to the personal principles that are being espoused.

Perhaps the most conspicuous (and unexpected) example of how leaving gaps in scenario narratives can precipitate discussion was with regard to gender of the people included. Across the scenarios all the characters were referred to in gender-neutral terms. However, frequently, students would refer to the gender of individuals in their explanations and in the discussions. Although sometimes little 
significance could be attached to this, as a masculine or feminine identity was simply used for convenience or brevity, often students had 'imagined' a gender on to a particular individual based on their characteristics as described in the scenario. Some notable patterns emerged - the possible cheat in the exam (scenario 5) was usually male; the same for the workplace 'boss' described in scenarios $7 \mathrm{a}$ and $7 \mathrm{~b}$. This, sometimes unconscious, gender labelling provided a good opportunity for tutors to steer discussions towards the role of gender stereotyping, the personal assumptions that they have made, and how the students might respond differently to men and women in varying contexts.

\section{5 , Promotes individual responsibility}

All the scenarios required the reader to make a decision on the appropriate course of action. The student responses indicated that more limited reflection tended to occur when responsibility for the decision could be passed easily on to other people in the narrative, e.g. a line manager (scenario 7b), or when a 'blind eye' could be turned to the situation, e.g. a student possibly cheating during an examination (scenario 5). Of course such passing on, or abdicating, of responsibility needs to be justified and certainly has ethical implications which might be teased out by a skilful tutor within the group discussions, but there is also a danger that such decisions might simply by taken as an 'easy way out', negating the need for further reflection. It therefore appears that effective ethical scenarios are generally those that portray circumstances when the reader is forced to take a proactive decision, assume individual responsibility and intervene directly in some way.

\section{Discussion and conclusion}

Developments both within and outside academia highlight the importance of enhancing the abilities and confidence of students to address ethical problems. However, the extent to which universities are achieving this goal in a sustained and systematic way is open to question (Boyd et al. 2008; Bruhn 2008; Escamez, Lopez and Jover 2008). Within the context of a drive to support graduates in the development of attributes which will allow them to negotiate increasingly fluid and challenging professional, civic and social spheres, this article has explored one way in which this topic might be addressed with at least a degree of success.

Like any teaching strategy, the relationship between what is intended and what is achieved is an uneven one and highly variable between students. There is no single definitive scenario which will transform student understanding of ethical decision-making. However, experience suggests that there are certain characteristics that can increase the potential effectiveness of ethical scenarios and these have been reported in this paper. It is plausible to incorporate all five of these features within a single ethical scenario. A commitment to an ongoing review and revision of scenarios in light of experience is highly recommended.

In some respects skilful scenario writing is about a achieving a balance. Too much detail can stifle discussion and force students towards a single, inevitable outcome, therefore undermining the potential for debate and reflection. A too minimalist approach can create frustration and disengagement, although an experienced facilitator should be able to encourage students to 'fill in the blanks' and then reflect on how this shapes personal decision-making. Finding some middle ground between realism and unrealism is also desirable. Although there are significant limits to what a scenario author can know about their students, tying a scenario too closely to known, real events 
can create discomfort and anxiety for both learners and tutors. By contrast, devising a scenario which appears 'far-fetched' or very distant from the experience of the students is also likely to undermine engagement.

The challenge of getting students to engage fully with the ethical scenarios is a significant one and, in common with many learning activities, the significance of perceived authenticity cannot be underestimated (Reeves, Herrington and Oliver 2002). In this case the desired goal was in-depth reflection on the circumstances described and, crucially, deciding on a course of action which reflects students' true perspectives and not those that they feel their tutors or peers want to hear. This is all the more important when considering ethical thinking because of the aspiration to get students to recognise and take ownership of a personal set of values and take responsibility for their decisionmaking, however difficult this may be. Occasionally, students would acknowledge in their responses that they might well act differently if they encountered the scenario circumstances in reality. This serves to highlight a limitation of SBL. It probably also shows a student concern with articulating what might be considered to be the 'right' answer, i.e. the one that the tutor is seeking, because they want to be perceived in a positive light. The fact that each tutorial was assessed may well have exacerbated this effect, even though the marking criteria placed emphasis on the ability to present and support a reasoned argument, not the position being taken.

Whilst the findings discussed are specific to ethical scenarios, much of the advice is transferable to the writing of all scenarios irrespective of their focus. Similarly, although there is a (often fairly minimal) geographical context provided for most of the scenarios, in fact there is little in the ethical problems that we have used that is subject-specific. They embrace challenges that university students are likely to encounter as they move within a typical web of social and professional interactions on a daily basis. In this respect, the findings are highly transferable to other academic disciplines. Furthermore, as Shulman (1992) and others remind us, it is essential to be clear at the outset about the theoretical principles that you want the scenarios to illustrate and devise their content accordingly. In this case, the opportunity for students to test the different approaches to ethical issues (e.g. utilitarian, rights, justice, common good and virtue approaches) was paramount.

This article has attempted to highlight the potential of well-written scenarios for enhancing the ethical thinking skills of students. Delivered in a systematic way, drawing on committed and skilful tutors, it has the potential to have some impact in isolation. However, such an approach is likely to prove more effective if situated within an institutional context that displays a wide-ranging commitment to the ethical development of its learners, and a concern to integrate it horizontally and vertically within programmes. How might this be achieved is beyond the scope of this paper, but at a programme level this is likely to include the clear signposting of ethical issues and debates as they appear within modules including those associated with the research process, and an encouragement to transfer ethical problem solving strategies between modules. It is also likely to include a sustained encouragement for learners to reflect on the development of their values, which could be discussed within the context of future employability aspirations for example. This might be embedded within an institutional strategy for personal tutor meetings, and therefore reflect a university-wide commitment to develop ethical sensitivity and moral reasoning as a graduate attribute.

Finally, this project has shown how the discussion of fictional scenarios can serve to highlight concerns and priorities in the real lives of undergraduates and potentially facilitate a deeper 
understanding of the contemporary student experience. This was most evident in two ways within the student responses: the consistent discussion of the importance of friendship networks and the frequent reference to the potential implications of decisions for assessment grades. These themes are also now emerging as a strand of some new, ongoing work by the authors exploring the potential of student-written scenarios and student-led facilitation of their discussion, an approach which is also conceived as another way of tackling the challenge of realism when devising and debating ethical scenarios. 
Realism, reflection and responsibility: The challenge of writing effective scenarios to support the development of ethical thinking skills

\section{Acknowledgements}

The authors would like to thank Rachel Hotson who contributed significantly to the qualitative data analysis which is discussed in this paper. 


\section{References}

Adam, R. 2010. "'Schooling for Hard Knocks': Using Scenario-Based learning (SBL) for Behaviour Management Skills in Pre-Service Teacher Education." In Preparing Graduates for the Professions Using Scenario- Based Learning, edited by E. Errington, 97-110. Brisbane: Post Pressed.

Aitken, P. 2010. "Scenario Based Disaster Health Education: War stories as Vicarious Experience." In Preparing Graduates for the Professions Using Scenario- Based Learning, edited by E. Errington, 75-84. Brisbane: Post Pressed.

Arthur, J. 2014. Being of Good Character. Birmingham: Jubilee Centre for Character and Virtues, University of Birmingham. Accessed 1 November 2016. http://www.jubileecentre.ac.uk/userfiles/jubileecentre/pdf/insight-series/ArthurJ.pdf

Bacigalupo, M., P. Kampylis, Y. Punie, G, and Van den Brande. 2016. EntreComp: The Entrepreneurship Competence Framework. Luxembourg: Publication Office of the European Union. doi:10.2791/593884.

Ballantyne, R., J. Bain, and J. Packer. 1999. "Researching University Teaching in Australia: Themes and Issues in Academics' Reflections." Studies in Higher Education 24 (2): 237-57.

Barfield, R. 2003. "Students' Perceptions of and Satisfaction with Group Grades and the Group Experience in the College Classroom." Assessment \& Evaluation in Higher Education 28 (4): 355370. doi: 10.1080/0260293032000066191.

Barnett, R. 2000. "Supercomplexity and the Curriculum." Studies in Higher Education 25 (3): 255-265.

Barrie, S. 2007. "A Conceptual Framework for the Teaching and Learning of Generic Graduate Attributes." Studies in Higher Education 32 (4): 439-458.

Barrow Cadbury Trust. 2010. Citizen Ethics in a Time of Crisis. Accessed 10 October 2016. http://www.barrowcadbury.org.uk/wp-content/uploads/2012/07/Citizens-Ethics.pdf

Bentley, Y. and S. Warwick. 2013. Students' Experience and Perceptions of Group Assignments. York: HEA. Accessed 27 October 2016. https://www.heacademy.ac.uk/system/files/gen_176_0.pdf

Bloom, B., M. Engelhart, E. Furst, W. Hill and D. Krathwohl. 1956. Taxonomy of Educational Objectives Volume I: The Cognitive Domain. New York: McKay.

Bloom, B., B. Masia and D. Krathwohl. 1964. Taxonomy of Educational Objectives Volume II: The Affective Domain. New York: McKay.

Boni, A., and J. Lozano. 2007. "The Generic Competences: An Opportunity for Ethical Learning in the European Convergence in Higher Education." Higher Education 54 (6): 819-831.

Boyd, W., R. Healey, S. Hardwick, M. Haigh, P. Klein, B. Doran, J. Trafford and J. Bradbeer. 2008. "'None of Us Sets Out To Hurt People': The Ethical Geographer and Geography Curricula in Higher Education." Journal of Geography in Higher Education 32 (1): 37-50. doi: 10.1080/03098260701731462. 
Bruhn, J. 2008. "Value Dissonance and Ethics Failure in Academia: A Causal Connection?" Journal of Academic Ethics 6 (1): 17-32.

Cameron, I. 2011. "Destinations and Pathways: The Curriculum Challenge." In Inspiring Academics: Learning with the World's Great University Teachers, edited by I. Hay, 79-86. Maidenhead: Open University Press.

Clarkeburn, H. 2002. "A Test for Ethical Sensitivity in Science." Journal of Moral Education 31 (4): 439453. doi: $10.1080 / 0305724022000029662$.

Clarkeburn, H., J. Downie, C.Gray, and R.Matthew. 2003. "Measuring Ethical Development in Life Sciences Students: A Study Using Perry's Developmental Model." Studies in Higher Education 28 (4): 443-456.

Cook-Sather, A. 2010. "Making Spaces to Learn." Curriculum Inquiry 40 (2): 281-294. doi: 10.1111/j.1467-873X.2010.00482.x.

Cope, M. 2010. "Coding Transcripts and Diaries." In Key Methods in Geography. 2nd ed., edited by N. Clifford, S. French and G. Valentine, 440-452. London: Sage.

Cousin, G. 2009. Researching Learning in Higher Education: An Introduction to Contemporary Methods and Approaches. London: Routledge.

Department for Business, Innovation and Skills. 2016. Success as a Knowledge Economy: Teaching Excellence, Social Mobility and Student Choice. London: HM Government.

Errington, E. ed. 2003. Developing Scenario-based Learning: Practical Insights for Tertiary Educators. Palmerston North: Dunmore Press.

Errington, E. 2010a. "Getting There: Choosing Scenarios to Meet Specific Professional Needs." In Preparing Graduates for the Professions Using Scenario- Based Learning, edited by E. Errington, 51-64. Brisbane: Post Pressed.

Errington, E. 2010b. "Introduction." In Preparing Graduates for the Professions Using Scenario- Based Learning, edited by E. Errington, 17-26. Brisbane: Post Pressed.

Errington, E. 2010c. "Preparing Graduates for the Professions: Achieving Employability through the Exploration of Near-world Scenarios." The International Journal of Interdisciplinary Social Sciences 5 (5): 1-10.

Errington, E. 2011. "Mission Possible: Using Near-World Scenarios to Prepare Graduates for the Professions." International Journal of Teaching and Learning in Higher Education 23 (1): 84-91.

Escamez, J., R. Lopez and G. Jover. 2008. "Restructuring University Degree Programmes: A New Opportunity for Ethics Education?" Journal of Moral Education 37 (1): 41-53.

Griffiths, S. 2009. "Teaching and Learning in Small Groups." In A Handbook for Teaching and Learning in Higher Education. 3rd ed., edited by H. Fry, S. Ketteridge and S. Marshall, 72-84. London: Kogan Page. 
Healey, R. and C.Ribchester. 2016. "Developing Ethical Geography Students? The Impact and Effectiveness of a Tutorial-Based Approach." Journal of Geography in Higher Education 40 (2): $302-$ 219. doi: 10.1080/03098265.2016.1141396.

Hennink, M., I. Hutter and A. Bailey. 2011. Qualitative Research Methods. London: Sage.

Hickey, R. and Taylor, P. 2010. "'It Happened Just Like We Talked About': Using Scenarios to Develop Professional Identity in Pre-Service Teachers." In Preparing Graduates for the Professions Using Scenario- Based Learning, edited by E. Errington, 133-146. Brisbane: Post Pressed.

Hill, A., C. Popovic, J. Eland, R. Lawton and N. Morton. 2010. "Creating Future-Proof Graduates Using Scenario-Based Learning." In Preparing Graduates for the Professions Using Scenario- Based Learning, edited by E. Errington, 27-38. Brisbane: Post Pressed.

Hill, J., H. Walkington and D. France. 2016. "Graduate Attributes: Implications for Higher Education Practice and Policy." Journal of Geography in Higher Education 40 (2): 155-163. doi: 10.1080/03098265.2016.1154932.

Holm, E. 2010. "Using Real-Life Scenarios In Law To Prepare Graduates For Professional Work Practices." In Preparing Graduates for the Professions Using Scenario- Based Learning, edited by E. Errington, 169-176. Brisbane: Post Pressed.

Kayaoğlu, M., Ş. Erbay, C. Flitner and D. Saltaş. 2016. "Examining Students' Perceptions of Plagiarism: A Cross-Cultural Study at Tertiary Level." Journal of Further and Higher Education 40 (5): 682-705. doi: 10.1080/0309877X.2015.1014320.

Kember, D., A. Ho and C. Hong. 2008. "The Importance of Establishing Relevance in Motivating Student Learning." Active Learning in Higher Education 9 (3): 249-263.

Klugman, C. and B. Stump. 2006. "The Effects of Ethics Training upon Individual Choice." Journal of Further and Higher Education. 30 (2): 181-192.

Lave, J. and E. Wenger. 1991. Situated Learning: Legitimate Peripheral Participation. Cambridge: Cambridge University Press.

Löfström, E. 2011. "'Does Plagiarism Mean anything? LOL.' Students' Conceptions of Writing and Citing." Journal of Academic Ethics 9 (4): 257-275. doi: 10.1007/s10805-011-9145-0.

Löfström, E. 2012. "Students' Ethical Awareness and Conceptions of Research Ethics." Ethics \& Behavior 22 (5): 349-361. doi: 10.1080/10508422.2012.679136.

Markkula Center for Applied Ethics. 2015. A Framework for Ethical Decision Making. Accessed 3 November 2016. https://www.scu.edu/ethics/ethics-resources/ethical-decision-making/aframework-for-ethical-decision-making/

McWilliam, E. 2009. "Teaching for creativity: from sage to guide to meddler." Asia Pacific Journal of Education 29 (3): 281-293. doi: 10.1080/02188790903092787.

MindTools. n.d. "Case Study-Based Learning". Accessed 11 October 2016. https://www.mindtools.com/pages/article/newlSS_94.htm. 
Nickson, A. 2010. "Social Work Ethics in Scenario Based Learning." In Preparing Graduates for the Professions Using Scenario- Based Learning, edited by E. Errington, 211-222. Brisbane: Post Pressed.

O'Leary, C. 2009. "An Empirical Analysis of the Positive Impact of Ethics Teaching on Accounting Students." Accounting Education 18 (4-5): 505-521.

Online Ethics Center for Engineering and Science. 2016. "What is the OEC?" Accessed 3 November 2016. http://www.onlineethics.org/

QAA. 2012. Enterprise and Entrepreneurship Education: Guidance for UK Higher Education Providers. Gloucester: QAA.

Race, P. 2014. Making Learning Happen: A Guide for Post-Compulsory Education. 3rd ed. London: Sage.

Rashid, U and E. Ventura-Medina. 2012. "Scenario Based E-Learning to Improve Problem Solving Skills." In Proceedings of the 23rd Annual Conference of the Australasian Association for Engineering Education, edited by L. Mann and D. Scott, 238-246. Melbourne: Engineers Australia.

Reeves, T., J. Herrington and R. Oliver. 2002. "Authentic Activities and Online Learning." In Quality Conversations, Proceedings of the 25th HERDSA Annual Conference. 562-567. http://ro.ecu.edu.au/cgi/viewcontent.cgi?article=4899\&context=ecuworks

Ritter, B. 2006. "Can Business Ethics be Trained? A Study of the Ethical Decision-Making Process in Business Students." Journal of Business Ethics 68 (2): 153-164.

Robinson, S. 2005. Ethics and Employability. York: HEA. Accessed 17 August 2016. https://www.heacademy.ac.uk/sites/default/files/esect ethics and employability.pdf

Sambell, K. 2016. "Assessment and Feedback in Higher Education: Considerable Room for Improvement?" Student Engagement in Higher Education Journal 1 (1): 1-14.

Shephard, K., T. Trotman, M. Furnari and E. Löfström. 2015. "Teaching Research Integrity in Higher Education: Policy and Strategy." Journal of Higher Education Policy and Management 37 (6): 615632. doi: 10.1080/1360080X.2015.1102823.

Self D., M. Olivarez, and D. Baldwin Jr. 1998. "The Amount of Small-Group Case-Study Discussion Needed to Improve Moral Reasoning Skills of Medical Students." Academic Medicine 73 (5): 52123.

Selwyn, N. 2008. "'Not Necessarily a Bad Thing...': A Study of Online Plagiarism Amongst Undergraduate Students." Assessment \& Evaluation in Higher Education 33 (5): 465-479.

Shulman, L. 1992. "Toward a Pedagogy of Cases." In Case Methods in Teacher Education, edited by J. Shulman, 1-30. New York: Teachers College Press.

Sorin, R. 2013. "Scenario-based learning: transforming tertiary teaching and learning." In: Proceedings of the 8th QS Asia Pacific Professional Leaders in Education Conference. 71-81. http://researchonline.jcu.edu.au/30512/ 
Taylor, C. 2015. A Guide to Ethics and Student Engagement Through Partnership. York: HEA. Accessed 27 October 2016. https://www.heacademy.ac.uk/resource/guide-ethics-and-studentengagement-through-partnership

The College of Optometrists. 2016. "Ethical scenarios". Accessed 3 November 2016. http://www.college-optometrists.org/en/professional-standards/ethical-scenarios/

Thomas, L. 2012. Building Student Engagement and Belonging in Higher Education at a Time of Change. London: Paul Hamlyn Foundation.

Varzaly, J. and J. Baron. 2009. "Innovating Corporate Governance Teaching Through Online ScenarioBased Learning." International Review of Business Research Papers 5 (3): 156-169.

Wilcox, P., S. Winn, and M. Fyvie-Gauld. 2005. "'It Was Nothing To Do With The University, It Was Just The People': The Role of Social Support in the First-Year Experience of Higher Education." Studies in Higher Education 30 (6): 707-722.

Zepke, N. and L. Leach. 2010. "Improving Student Engagement: Ten Proposals for Action." Active Learning in Higher Education 11 (3): 167-177. 